\title{
Quais os cuidados antes da operação? Termo de consentimento sempre?
}

\section{What cares to be taken before surgery? Informed consent every time?}

TCBC-SP - Fernando CoRdeiro

U ma das perguntas mais frequentes no dia-a-dia do médico refere-se aos cuidados que antecedem uma intervenção cirúrgica. Uns responderiam com uma lista de exames subsidiários que segundo informações de amigos, colegas ou textos científicos protegeria o médico de futuras demandas legais e outros responderiam com suas ações baseadas no conhecimento medico lastreado pela ciência e pela força de suas evidencias.

O médico é instruído para se comportar com retidão, utilizando-se dos melhores métodos investigativos e sempre observando as ações que comportem os menores danos.

O paciente, porém, que irá se submeter ao procedimento, por sua vez acredita que o ato médico praticado é infalível, irá resolver todos os seus problemas e que não comporta erros ou danos.

Esta relação medico-paciente, porém, está longe de ser definitivamente resolvida. Primeiro porque os médicos, aprendem nas escolas médicas, principalmente, a parte técnica da sua atividade: como examinar, como diferenciar os problemas e como tratar aquilo que acreditam ser a causa das angústias do seu paciente. E, segundo, porque na prática diária é que aprendem que as normas legais devem ser cumpridas de maneira efetiva e cotidiana.

O exercício médico não é diferente de qualquer outro ramo de atividade profissional. Não deve errar. Cada um aceita a sua responsabilidade e arca com os danos que eventualmente causar.

Por isso, cada um de nós deve tomar o máximo cuidado para que, se imprevistos acontecerem, possam estes, serem responsabilizados não por conta de faltas ou falhas profissionais mas sim por conta do imponderável, por conta da natureza humana.

E por quê isso? Porque a sociedade civil entendeu que a atividade de alguns profissionais, a medicina em particular, depende não apenas do esforço daquele que produz o ato mas também das condições individuais daquele que solicita a ação. Desta forma é que se instituiu que a atividade profissional médica não espera um resultado final mas a observância das condições em que este ato foi realizado: se, com cuidado, observando-se as características individuais de cada um, verificando as condições mórbidas mais frequentes e, principalmente, se a terapêutica contém a menor possibilidade de consequências danosas àquele que é sub- metido ao procedimento. É a chamada Responsabilidade Civil Subjetiva.

Então, agora, quais os cuidados pré-operatórios? Antes de pensarmos em exames laboratoriais, primeiramente, devemos ter sempre em mente que o médico não é um adivinho e que, como todo ser humano, não sabe tudo (aliás, não sabe nada). Ele aprende, de maneira sistemática, a observar sinais e sintomas e, com estes, realizar as famosas hipóteses diagnósticas. São hipóteses pois necessitam de confirmação. São as mais prováveis, aquelas mais frequentemente vistas por outros médicos e relatadas ao mundo, especialista ou não.

E como realizar esta prova? Quer seja por um teste terapêutico (utilizar-se de um medicamento e verificar se o seu uso causou uma regressão da lesão com consequências colaterais mínimas), quer seja por um exame laboratorial diagnóstico complementar ou finalmente, pela extirpação daquele elemento anormal. Devemos sempre lembrar que a confirmação da anormalidade deste órgão retirado é mandatório para a satisfação daquele que se submete a tal procedimento.

Mas se é só isso, por que não realizar todos os exames possíveis ou ainda testar todas as drogas existentes ou ainda, retirar tudo aquilo que não nos parece normal? Por duas razões bem simples: O custo financeiro da realização de todos os exames laboratoriais possíveis tornaria a economia social inviável. Os danos ocasionados por estes atos não seriam previsíveis e as lesões consequentes poderiam ser mais importantes.

Este é o motivo da importância do ato médico: pesquisar, segundo um método científico, as hipóteses diagnósticas mais factíveis e prová-las. Assim, ouvir as queixas, pesquisar as condições de vida, individuais e sociais, examinar o paciente à procura de sinais que possam trazer à luz problemas que acontecem na intimidade de cada corpo e só aí, propor hipóteses que merecem, prioritariamente serem provadas.

Então não devemos realizar exames complementares não pertinentes à nossa hipótese diagnóstica? Evidentemente que não pois, se assim o fizermos, estaremos nos comportando não como o profissional que investiga mas como o leigo que especula. Mas e as enfermidades que podem associar-se e trazer maiores riscos ao paciente quando da realização de um procedimento médico? Estas devem também ser investigadas e poderão fazer parte da hipótese diagnóstica final para só então serem provadas. 
Portanto, primeiro cuidado: pratique o método investigativo aprendido, sempre! Faça os questionamentos adequados, ouça as queixas pertinentes ao fato e, examine criteriosamente o paciente.

Mas, e as normas legais? Como provar que todos estes fatos relatados ocorreram?

A sociedade civil, ao entender que o médico não poderia ter certeza do resultado final de seus atos, responsabilidade civil subjetiva, ao criar normas específicas sobre as relações de consumo, Código de Defesa e Proteção ao Consumidor, excluiu esta classe de responder por qualquer resultado danoso de maneira direta, objetiva. Mas exigiu que este provasse que os realizou de maneira zelosa, cuidadosa e tempestiva. Assim, obriga o médico a documentar tudo aquilo que fez, de maneira que, quando questionado, possa apresentar à sociedade o histórico deste ato médico. Este documento denominado prontuário médico, é o instrumento que caracteriza a realização do método. Este é imprescindível à atividade profissional devendo ser realizado de maneira completa, no momento do ato médico, constando todos os fatos, os resultados do exame clinico, dos exames complementares e as hipóteses diagnósticas aventadas. Este prontuário deve, principalmente, ser realizado em prol daquele que se submete ao procedimento: o paciente. Este é o motivo pelo qual, o documento deve ser escrito de maneira legível, sem abreviações, em linguagem que possa ser entendida por uma pessoa mediana da comunidade pois, a sociedade o caracteriza como sendo de propriedade do paciente e obriga o profissional a guardá-lo para que, em casos em que ocorram divergências sobre os fatos, alguém possa examiná-lo de maneira imparcial.

Mas como é que uma pessoa, sem conhecimento específico, pode ter certeza de que tudo aquilo que lhe é proposto não irá lhe ocasionar um dano maior do que aquele que ele já possui? Como saber se as ações realizadas pelo profissional médico são as melhores para ele? Como acreditar em alguém?

Para isso, como em qualquer relação pessoal, a informação é o melhor instrumento. Informação completa, que possa ser entendida também por uma pessoa de conhecimentos medianos, que contenha não só os benefícios da ação mas eventuais malefícios que possam ocorrer e que permita ao indivíduo que a recebe, a possibilidade de aceitar ou não tais procedimentos. Informação que traga ao paciente, quais serão os seus custos financeiros, imediatos e prováveis, de que maneira serão acertados e quais os eventuais problemas que poderão acontecer em decorrência da ação proposta.

Por este motivo, vários documentos legais, médicos ou não, declaram este dever de informação (Resolução CFM 1931/2009, artigos 22, 34, 101 e 1033; Código de Defesa e Proteção ao Consumidor - lei 8078/1990, artigos $4^{\circ}$ e $6^{\circ} 2$; Constituição Federal de 1988 , artigos 5, II, $\left.\mathrm{XIV}^{4}\right)$. Somente em situações excepcionais, quando em risco a vitalidade do indivíduo, a informação pode ser poster- gada, assumindo o profissional a responsabilidade pela ação proposta.

Assim, chegamos a um ponto crucial. Muito se fala em Termo de Consentimento mas, qual o seu significado? Quem pode exigi-lo? Quem deve realizá-lo? Em que momento realizá-lo?

Utilizado de maneira aleatória, como sinonímia de "termo de consentimento", encontramos, entre outros, "consentimento informado" (significando aquiescência do paciente para realização de procedimento, após ter sido informado sobre as finalidades e eventuais complicações, de maneira tácita, não expressa), "consentimento livre e esclarecido" (com o significado de aquiescência, de maneira a preservar a autonomia do paciente após informação sobre as finalidade e complicações. Também de maneira tácita) e "termo de consentimento informado livre e esclarecido".

Este último, merece algumas considerações importantes pois é utilizado de maneira inadequada, tanto por profissionais de saúde, profissionais do Direito e pela população em geral. Este documento surgiu nos anos 1767, na Inglaterra, quando dois médicos decidem tomar uma conduta médica sem consultar o paciente e posteriormente nos Estados Unidos, em 1957, com a finalidade de colocar "à termo" as informações dadas aos voluntários de estudos experimentais, sobre o procedimento a ser realizado, com as explicações sobre riscos, efeitos adversos, após explicação exaustiva, aceito de maneira autônoma e, formalmente, assinado pelas partes envolvidas e testemunhado. Servia, e serve, para proteger aquele que, voluntariamente, se expõe a riscos em benefício de estudos experimentais clínicos.

Não se pode confundir o significado de consentimento para realização de um ato médico com o consentimento para a realização de um trabalho experimental, principalmente porque nesse caso, o indivíduo não é portador de problemas outros e experimenta riscos desconhecidos na sua integralidade.

O ato médico é regido por um acordo tácito entre as partes e não um contrato formal, acordo este realizado quando o paciente se apresenta ao médico, pagaIhe, participa da entrevista e consente com o exame físico. Aceita este exame, escuta as ponderações do profissional e executa ou não suas sugestões, sem ser coagido a fazêlo. Ouve a respeito dos riscos do procedimento, riscos estes que podem ocorrer em determinado número de pessoas da população e aos quais o paciente também está sujeito. Se the forem convenientes e se o desejar, correr estes riscos, os procedimentos Ihe serão impostos.

Por que os aceita? Por que participar da chance de ter um inconveniente em decorrência do tratamento? Por ter sido adequadamente informado e por acreditar que o profissional que lhe sugeriu tal terapêutica o fez de maneira perita, prudentemente e no momento adequado. Também o faz pois acredita que, caso os efeitos adversos surjam, pode contar com a ajuda deste mesmo profissional para auxiliá-lo na sua resolução. 
Mas então, o que significa "termo"? Significa redigir um documento se responsabilizando, formalmente, agora não somente por praticar o exercício médico de maneira correta mas, por consequências aleatórias que podem surgir desta terapêutica. Mas o médico não tem que dizer e assumir todos os riscos? Como a medicina é uma atividade inexata, qualquer um que a pratique só poderá recordar-se dos eventos mais frequentes e descritos na literatura médica. Qualquer fato menos observado ou que involuntariamente seja esquecido não denota falta de informação mas algo que pode ocorrer com qualquer ser humano. É importante lembrar, novamente, que cabe ao profissional médico, realizar suas ações com perícia, prudência e zelosamente.

Neste caso, como o paciente poderá demonstrar que o profissional médico não cumpriu com os seus deveres? Com um prontuário médico completo. adequadamente redigido e que poderá ser solicitado a qualquer momento por este paciente.

Por que não colocar o Consentimento Informado, Livre e Esclarecido à termo? Porque este documento precisaria ser o mais completo possível, sem omitir nenhuma possibilidade remota e principalmente ser individualizado, não devendo ser realizado em série com o risco de ser utilizado como prova contrária ao próprio realizador.

Também porque este documento transforma substancialmente a atividade médica que, consagrada pe- los Códigos e pela sociedade, é uma atividade de fins e que não promete um resultado final. Para se avaliar danos provocados pelo médico há que provar culpabilidade, ou seja, sem a intenção implícita de provocar lesões.

Agora, se por qualquer motivo, escuso ou não, o profissional não seguir as regras de conduta determinadas pela sociedade, como por exemplo "prometer" determinado resultado, mesmo que por apresentação de fotos ou modelos fotográficos, arca com os prejuízos de ter sua atividade regida não mais como atividade de meio mas como atividade profissional de fim, responsabilizando-se pelo resultado esperado e sem a análise de culpa. Passa a ter a sua atividade regida pelo Código de Defesa do Consumidor no seu artigo 14, caput: "O fornecedor de serviços responde, independentemente da existência de culpa, pela reparação dos danos causados aos consumidores por defeitos relativos à prestação dos serviços, bem como por informações insuficientes ou inadequadas sobre sua fruição e riscos".

Não se trata aqui de incentivar o médico a não informar correta e adequadamente o seu paciente, ao contrário, é dever do médico fazê-lo, de maneira cordata, com palavras que possam ser entendidas pelo seu interlocutor e caso este não tenha capacidade de entender, convocar um responsável legal para que todas as informações prestadas sejam utilizadas pelo paciente na tomada de sua decisão. O documento cabal para prova dos fatos é sem sombra de dúvidas o prontuário médico adequado. 